\title{
When do marginal seas and topographic sills modify the ocean density structure?
}

\author{
K. D. Stewart, ${ }^{1}$ G. O. Hughes, ${ }^{1}$ and R. W. Griffiths ${ }^{1}$ \\ Received 20 January 2011; revised 14 April 2011; accepted 18 May 2011; published 23 August 2011.
}

[1] We ask what effect marginal seas at high latitudes have on the abyssal densities and stratification of the oceans. Although marginal seas are not necessary for the formation of dense abyssal waters, topographic sills tend to restrict exchange flows and increase density differences. Laboratory experiments with a steady state large-scale overturning circulation, forced by a gradient in surface temperatures or heat fluxes, show that a marginal sea and topographic sill influence the abyssal density when the sill depth is less than twice the oceanic thermocline depth. The overflow over shallow sills interacts directly with the surrounding thermocline stratification, decreasing the abyssal density relative to an ocean with no marginal sea and increasing the density difference between the sea and the ocean. Experiments show that the effect of the sill depends on the surface boundary conditions and indicate a larger response for conditions approaching a prescribed distribution of temperature rather than of heat flux. Application of the results to the North Atlantic circulation suggests that the Greenland-Scotland Ridge is shallow enough to lead to a significant reduction of the density of North Atlantic Deep Water, and this is consistent with the conclusions from an analysis of water mass properties. The Greenland-Scotland Ridge is therefore likely to have a significant effect on the density structure and heat transport in the global oceans.

Citation: Stewart, K. D., G. O. Hughes, and R. W. Griffiths (2011), When do marginal seas and topographic sills modify the ocean density structure?, J. Geophys. Res., 116, C08021, doi:10.1029/2011JC006980.

\section{Introduction}

[2] The observation that Antarctic Bottom Water (AABW) originates from the likes of the Ross and Weddell Seas [Orsi et al., 1999], and that North Atlantic Deep Water (NADW) forms from surface waters transformed in the Nordic and Labrador Seas [Dickson and Brown, 1994; Schott et al., 2004], might be interpreted as evidence that high-latitude marginal seas are necessary for the formation of Deep and Bottom waters. However, the densification of water in these seas, which is assisted by the restriction of circulation by topographic sills, does not necessarily lead to a greater density of abyssal ocean waters. Previous studies [e.g., Stommel, 1962; Winton, 1995] have shown that localized dense water formation at high latitudes does not require such enclosing topography. Thus we ask to what extent deep and bottom water formation at high latitudes (which is a consequence of the large-scale meridional gradient of surface buoyancy fluxes) [Stommel, 1962] is modified by the presence of shallow or semienclosed seas at high latitudes? The existence of these seas may simply make them the preferred sites for the

\footnotetext{
${ }^{1}$ Research School of Earth Sciences, Australian National University, Acton, ACT, Australia.

Copyright 2011 by the American Geophysical Union. 0148-0227/11/2011JC006980
}

production of densest water, or for the greatest rate of production of density anomaly (i.e., largest buoyancy flux). The answer to the above question and to what abyssal densities would exist in the absence of marginal seas cannot readily be determined from observations in the present oceans.

[3] For our purposes a marginal sea is either a relatively shallow semienclosed sea connected to the main ocean basin, or a second deep but smaller basin separated from the main ocean by a relatively high (i.e., shallow) topographic sill. Dense outflows from marginal seas form the major sinking legs of the meridional overturning circulation (MOC) and help maintain the abyssal density stratification [Saunders, 1996, 2001; Bryden and Nurser, 2003]. Insights into the dynamics of the MOC have been obtained through simplified numerical models and laboratory experiments with surface buoyancy forcing (or equivalently forcing at the horizontal base) of a basin [e.g., Rossby, 1965; Bryan and Cox, 1967; Bryan, 1987; Park and Bryan, 2000; Mullarney et al., 2004; Wang and Huang, 2005]. When the boundary conditions are steady and the circulation is in equilibrium, there is a zero net vertical buoyancy flux through any level [Paparella and Young, 2002; Hughes et al., 2007; Hughes and Griffiths, 2008]. The destabilizing buoyancy created by surface cooling is carried to depth in a dense and localized sinking current. At each depth this buoyancy transport is matched by a stabilizing flux that is delivered to depth (following the heat input to the low-latitude ocean surface) by Ekman pumping and vertical diffusion (as envisaged by Munk [1966] in a 
vertical advection-diffusion balance). There is also a substantial 'short-circuit' path for heat transport to the bottom by advection in the descending dense current, which results from turbulent entrainment of surrounding (relatively warm) water, particularly from thermocline depths [Hughes and Griffiths, 2006]. Thus any factors influencing the density or mass flux in the dense overflows are likely to affect the abyssal densities and the ocean density stratification [Bryden and Nurser, 2003].

[4] Topographic sills are a key factor in exchange flows between ocean basins, as they can give rise to hydraulic control of the mass flux in dense overflows [Killworth, 1995; Whitehead, 1998; Hansen and Østerhus, 2007]. Control of the mass exchange by sills also implies control of the density difference between the semienclosed sea and the ocean. In a long-term steady state, the lateral density difference must be large enough to force an exchange that facilitates a net export of heat from the semienclosed sea to balance the surface cooling of the sea. Shallower sills will tend to give rise to larger density differences. Thus sills could potentially govern the abyssal stratification. Simple experiments and numerical solutions have demonstrated the effects of sills and relative basin sizes on the density fields in two basins connected by a sill overflow when one basin is forced by a destabilizing buoyancy flux in the form of a turbulent plume [Wong and Griffiths, 2001]. Other experiments provide a relationship between the surface buoyancy flux in a marginal sea and the resulting baroclinic mass exchange flux in the sill overflow into an infinitely large basin [Finnigan and Ivey, 1999, 2000; Finnigan et al., 2001], but these studies did not address the role of forcing, circulation and density stratification in the large basin and were not in a steady state, with zero net surface heat input, as might be supposed for the oceans in a fixed climate regime.

[5] Observations of the Greenland-Scotland Ridge (GSR) overflows [e.g., Voet and Quadfasel, 2010; Fer et al., 2010] highlight the important role that mixing and entrainment of ambient waters play in setting the properties of NADW, ventilating the deep North Atlantic and setting the global ocean density stratification. The Strait of Gibraltar is another example of an overflow modified by mixing (in the vicinity of Carmarinal Sill) with the North Atlantic lower thermocline waters, leading to a density difference between the "Mediterranean Waters" in the Mediterranean and in the North Atlantic [Bryden et al., 1994]. The parameterization of such overflows, particularly the associated entrainment process, have been identified as a weakness of GCMs and is the focus of much current work [e.g., Cenedese and Adduce, 2010; Legg et al., 2009; Danabasoglu et al., 2010; Wells et al., 2010].

[6] We report the results of laboratory experiments examining the steady state circulation in systems consisting of a larger (but finite) basin connected to a smaller basin over a topographic sill. The large-scale circulation is driven by differential heating that mimicks the global meridional gradient applied at the ocean surface and which is independent of the sill location. The roles of sill depth, location and crossstream shape are examined for both imposed temperature difference and imposed heat flux boundary conditions. The experimental apparatus and method are described in section 2 . The results of the experiments are presented in section 3 and discussed in section 4. The implications of the results for the global ocean circulation are considered in section 5 .

\section{Experimental Apparatus and Method}

[7] The experiments were carried out in a tank with internal dimensions of length $L=1.25 \mathrm{~m}$, width $W=0.305 \mathrm{~m}$, and depth $D=0.2 \mathrm{~m}$ (Figure 1). The tank was similar to that used by Mullarney et al. [2004] but double the width and with a triple glazed lid. It incorporated a $10 \mathrm{~mm}$ thick copper base and was filled to capacity with deaired water. The acrylic sidewalls were double glazed and the gap filled with argon; the solid endwalls were $20 \mathrm{~mm}$ thick. The entire tank was thermally insulated with $0.1 \mathrm{~m}$ expanded polystyrene foam board encased in aluminium foil. The experiments were conducted in a special constant temperature laboratory held at $30 \pm 0.3^{\circ} \mathrm{C}$. The copper base was in direct contact with heating and cooling systems; either two water heat exchangers (each $0.6 \times 0.305 \mathrm{~m}$ ), or one water heat exchanger and an electric heating mat. The heat source and sink were insulated from each other by a $50 \mathrm{~mm}$ spacer placed between them. The direct transport of heat between the source and sink by conduction along the copper base was estimated from a numerical solution of the heat equation and found to be less than $0.3 \%$ of the total heat input. The insulating side and endwalls extended downward to completely surround the heating/cooling system and the whole arrangement was insulated beneath by $0.1 \mathrm{~m}$ of foam board.

[8] One set of boundary conditions consisted of a uniform, constant (input) heat flux, $F_{T}$ through one half of the base, and a uniform, constant temperature on the other half of the base. The total heat input from the heating power controller was set between 210 and $420 \mathrm{~W}\left(F_{T}=1148\right.$ and $2295 \mathrm{~W} \mathrm{~m}^{-2}$, respectively) and most runs were with $280 \mathrm{~W}$ $\left(F_{T}=1530 \mathrm{~W} \mathrm{~m}^{-2}\right)$. The power supply controller held the input power constant to within $0.1 \mathrm{~W}$. The applied temperature at the right-hand half of the base was maintained by recirculating water at $16 \pm 0.02^{\circ} \mathrm{C}$ from a constant temperature bath. In these experiments the applied heat input must, in a steady state and for a suitable time average, be matched by the heat removed at the cooled region. Hence this case is referred to below as "imposed heat flux" (Table 1). The second set of boundary conditions consisted of the same applied temperature on the right half of the base and a higher applied temperature, from a second water bath at $40 \pm 0.02^{\circ} \mathrm{C}$, on the left half. Thus the temperature difference in the base was held at $\Delta T=24^{\circ} \mathrm{C}$, and this case is hereinafter referred to as "imposed temperature difference". This temperature difference was chosen to match that measured in a reference experiment with an imposed heat flux of $280 \mathrm{~W}$ and no sill.

[9] Eight fast response thermistor probes were inserted into the tank through access tubes in the lid. Six of the thermistors could be traversed vertically through the tank depth to obtain temperature profiles. Measurement noise in the profiles was reduced by rapid sampling and spatial filtering, yielding an effective vertical resolution of $0.5 \mathrm{~mm}$. A thermistor was fixed within the copper base plate toward each the four corners, positioned $0.1 \mathrm{~m}$ and $0.075 \mathrm{~m}$ from the endwall and sidewall, respectively. A thirteenth therm- 


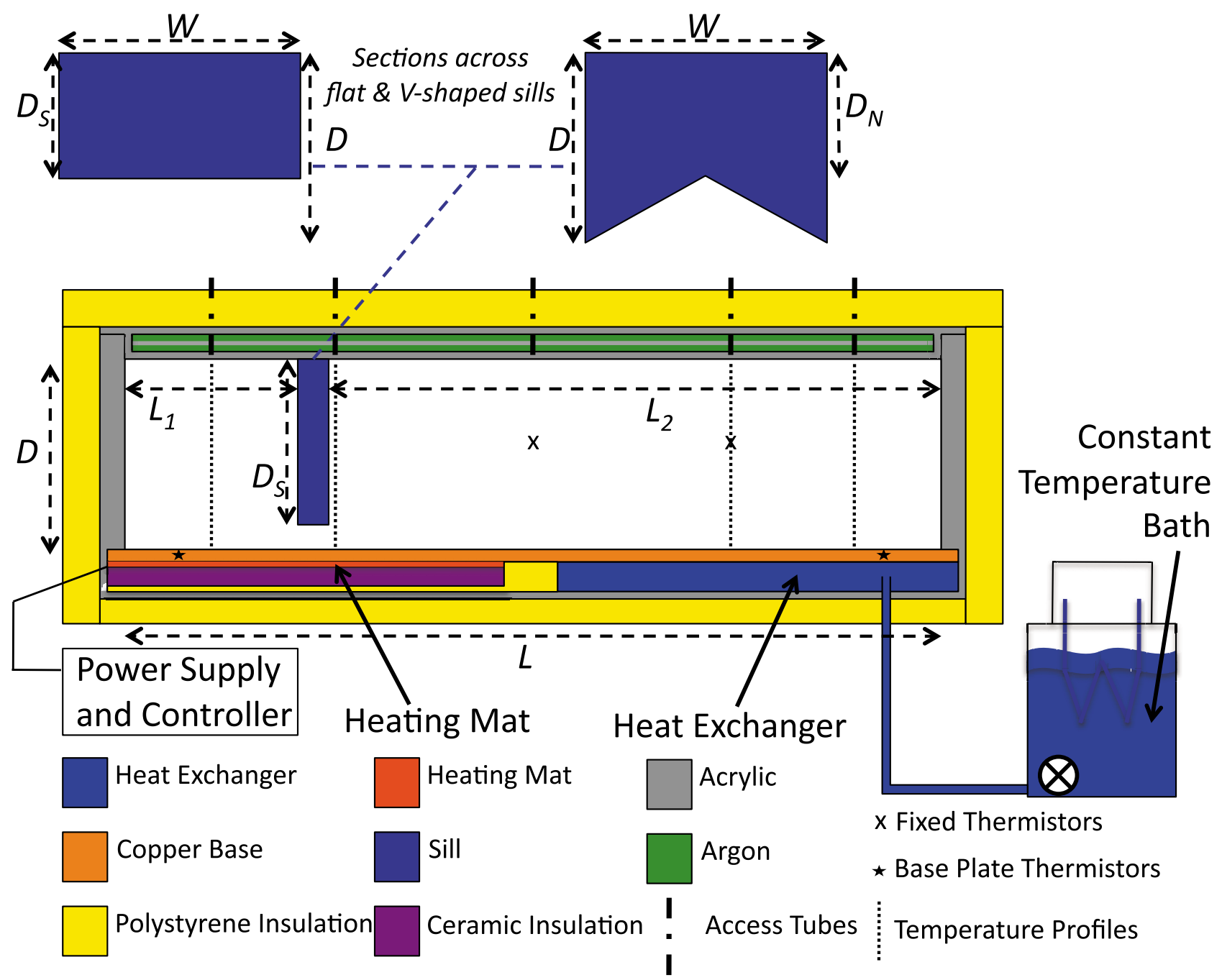

Figure 1. Schematic diagram of apparatus for the experiments with an imposed heat flux. Vertical dotted lines show the location of the six traversing thermistors; one thermistor each for the profiles closest to the endwalls, and two thermistors each for the other two profiles (one on, and the other $100 \mathrm{~mm}$ off, the centerline). The normalized temperature profiles (Figure 4) are from the two centerline thermistors above the cold plate, and the middle-depth temperatures (Figure 5) are from the thermistors closest to the endwalls. The sill is shown for a basin length ratio $L_{1} / L_{2}=1 / 4$, but ratios of 1 and 4 were also used. Cross-stream sections of the flat and V-shaped sill geometries (rotated from the vertical plane across the tank width) are also shown. A uniform heat flux is delivered to the base on the left half. For runs with imposed temperature difference, the heating element and underlying ceramic insulation were replaced with a heat exchanger identical to that shown under the right half of the base and connected to a second water bath. In both systems at thermal equilibrium there was a zero net heat input to the tank.

istor logged the room temperature. Temperature changes could be measured to $\pm 0.01^{\circ} \mathrm{C}$.

[10] Topographic sills were simple vertical barriers of $50 \mathrm{~mm}$ impermeable polystyrene foam that sealed against the tank walls and lid. The barriers were at the top of the tank rather than against the base, as the whole system was inverted relative to the oceans for practical reasons. For the majority of the experiments the sill was positioned to give a ratio of basin lengths $L_{1} / L_{2} \approx 1 / 4$, with the smaller basin on the left over the heating region. The length ratios 1 and 4 were also examined (Table 1). The barrier height $D_{S}$ was such that normalized gap heights $R_{D}=\left(D-D_{S}\right) / D$ varied over the range $0 \leq R_{D} \leq 1$ for imposed temperature difference and $0.05 \leq R_{D} \leq 1$ for imposed heat flux (note that $R_{D} \rightarrow 0$ was not a useful limit in the latter case because the net heat flux into the small basin would lead to a continual temperature increase). A small number of experiments were carried out to examine the effect of a nonuniform sill geometry: in these runs the sill had a triangular notch (a V shape spanning the width of the tank at its base and of height $D-D_{N}$ at the apex) as a crude representation of an ocean channel (Figure 1). In these cases the normalized gap height, defined as $R_{D}=\left(D-D_{N}\right) / D$, was varied over the range $0.1 \leq$ $R_{D} \leq 0.95$, where $D_{N}$ is the height of the triangular opening 
Table 1. Experimental Conditions and Calculated Values for Key Dimensionless Parameters

\begin{tabular}{|c|c|c|c|c|c|c|c|c|c|}
\hline & $\begin{array}{l}\text { Boundary } \\
\text { Condition }^{\mathrm{a}}\end{array}$ & Watts & $R a_{F}(R a)$ & Sill & $R_{D}$ & $L_{1} / L_{2}$ & $\delta / D$ & $N u$ & $R_{0}$ \\
\hline 1 & flux & 280 & $1.85 \times 10^{14}$ & flat & 1 & $1 / 4$ & 0.055 & $1.45 \times 10^{2}$ & 17.79 \\
\hline 2 & flux & 280 & $2.06 \times 10^{14}$ & flat & 0.05 & $1 / 4$ & 0.203 & $1.03 \times 10^{2}$ & 0.8005 \\
\hline 3 & flux & 280 & $1.97 \times 10^{14}$ & flat & 0.1 & $1 / 4$ & 0.103 & $1.33 \times 10^{2}$ & 1.601 \\
\hline 4 & flux & 280 & $1.89 \times 10^{14}$ & flat & 0.15 & $1 / 4$ & 0.064 & $1.42 \times 10^{2}$ & 2.668 \\
\hline 5 & flux & 280 & $1.87 \times 10^{14}$ & flat & 0.2 & $1 / 4$ & 0.059 & $1.44 \times 10^{2}$ & 3.558 \\
\hline 6 & flux & 280 & $1.87 \times 10^{14}$ & flat & 0.25 & $1 / 4$ & 0.060 & $1.44 \times 10^{2}$ & 4.447 \\
\hline 7 & flux & 420 & $3.74 \times 10^{14}$ & flat & 0.1 & $1 / 4$ & 0.077 & $1.44 \times 10^{2}$ & 1.797 \\
\hline 8 & flux & 210 & $1.30 \times 10^{14}$ & flat & 0.1 & $1 / 4$ & 0.134 & $1.25 \times 10^{2}$ & 1.420 \\
\hline 9 & flux & 420 & $3.53 \times 10^{14}$ & flat & 1 & $1 / 4$ & 0.049 & $1.52 \times 10^{2}$ & 20.41 \\
\hline 10 & flux & 210 & $1.22 \times 10^{14}$ & flat & 1 & $1 / 4$ & 0.062 & $1.35 \times 10^{2}$ & 16.13 \\
\hline 11 & $\Delta T$ & - & $\left(6.26 \times 10^{11}\right)$ & flat & 0 & $1 / 4$ & 0.055 & - & 0 \\
\hline 12 & $\Delta T$ & - & $\left(1.48 \times 10^{12}\right)$ & flat & 0.05 & $1 / 4$ & 0.083 & - & 0.8224 \\
\hline 13 & $\Delta T$ & - & $\left(1.57 \times 10^{12}\right)$ & flat & 0.1 & $1 / 4$ & 0.091 & - & 1.645 \\
\hline 14 & $\Delta T$ & - & $\left(1.56 \times 10^{12}\right)$ & flat & 0.125 & $1 / 4$ & 0.074 & - & 2.284 \\
\hline 15 & $\Delta T$ & - & $\left(1.56 \times 10^{12}\right)$ & flat & 0.15 & $1 / 4$ & 0.062 & - & 2.741 \\
\hline 16 & $\Delta T$ & - & $\left(1.55 \times 10^{12}\right)$ & flat & 0.25 & $1 / 4$ & 0.056 & - & 4.569 \\
\hline 17 & $\Delta T$ & - & $\left(1.55 \times 10^{12}\right)$ & flat & 1 & $1 / 4$ & 0.055 & - & 18.28 \\
\hline 18 & flux & 280 & $2.10 \times 10^{14}$ & $\mathrm{~V}$ & 0.1 & $1 / 4$ & 0.153 & $1.25 \times 10^{2}$ & 1.779 \\
\hline 19 & flux & 280 & $1.99 \times 10^{14}$ & $\mathrm{~V}$ & 0.15 & $1 / 4$ & 0.088 & $1.35 \times 10^{2}$ & 2.668 \\
\hline 20 & flux & 280 & $1.96 \times 10^{14}$ & $\mathrm{~V}$ & 0.2 & $1 / 4$ & 0.074 & $1.37 \times 10^{2}$ & 3.558 \\
\hline 21 & flux & 280 & $1.93 \times 10^{14}$ & $\mathrm{~V}$ & 0.25 & $1 / 4$ & 0.066 & $1.39 \times 10^{2}$ & 4.447 \\
\hline 22 & flux & 280 & $1.89 \times 10^{14}$ & $\mathrm{~V}$ & 0.95 & $1 / 4$ & 0.057 & $1.42 \times 10^{2}$ & 16.90 \\
\hline 23 & $\Delta T$ & - & $\left(1.38 \times 10^{12}\right)$ & flat & 0.05 & 1 & 0.695 & - & 0.8224 \\
\hline 24 & $\Delta T$ & - & $\left(1.61 \times 10^{12}\right)$ & flat & 0.05 & 4 & 0.880 & - & 0.8224 \\
\hline 25 & $\Delta T$ & - & $\left(1.55 \times 10^{12}\right)$ & flat & 0.15 & 1 & 0.065 & - & 2.741 \\
\hline 26 & $\Delta T$ & - & $\left(1.55 \times 10^{12}\right)$ & flat & 0.15 & 4 & 0.065 & - & 2.741 \\
\hline 27 & flux & 280 & $2.21 \times 10^{14^{\prime}}$ & flat & 0.05 & 1 & 0.890 & $8.75 \times 10$ & 0.8005 \\
\hline 28 & flux & 280 & $2.24 \times 10^{14}$ & flat & 0.05 & 4 & 0.880 & $1.13 \times 10^{2}$ & 0.8005 \\
\hline 29 & flux & 280 & $1.90 \times 10^{14}$ & flat & 0.15 & 1 & 0.069 & $1.41 \times 10^{2}$ & 2.668 \\
\hline 30 & flux & 280 & $1.90 \times 10^{14}$ & flat & 0.15 & 4 & 0.055 & $1.41 \times 10^{2}$ & 2.668 \\
\hline
\end{tabular}

a'Boundary conditions of imposed heat flux and imposed temperature difference are denoted by "flux" and " $\Delta T$ ", respectively.

at its vertex. For these V-shaped sills, only imposed heat flux was used and the length ratio of the two basins was fixed at $1 / 4$.

[11] In addition to $R_{D}$ and $L_{1} / L_{2}$, dimensionless parameters governing the experiments were a Rayleigh number (either $R a$ based on the imposed temperature difference or $R a_{F}$ based on the imposed flux),

$$
R a=\frac{g \alpha \Delta T L^{3}}{\nu \kappa_{T}} \quad \text { or } \quad R a_{F}=\frac{g \alpha F_{T} L^{4}}{\rho c_{p} \nu \kappa_{T}^{2}}
$$

the aspect ratio,

$$
A=\frac{D}{L}
$$

and the Prandtl number,

$$
\operatorname{Pr}=\frac{\nu}{\kappa_{T}}
$$

where $g$ is the acceleration due to gravity, and $\alpha, \nu, \kappa_{T}, \rho$ and $c_{p}$ are the thermal expansion coefficient, kinematic viscosity, thermal diffusivity, density and specific heat capacity of water, respectively.

[12] The focus in this study is on the effect of a sill. The other global parameters were therefore fixed as far as was practical: for the purpose of calculating those above the water properties were evaluated at the temperature measured at middle depth in the larger basin. The aspect ratio $A=0.16$ and the Prandtl number $\operatorname{Pr}=4.7 \pm 0.2$, the latter depending slightly upon the temperature in each experiment. Unless stated otherwise (Table 1), the results are for runs with a basin length ratio $L_{1} / L_{2} \approx 1 / 4$ and either an imposed heat flux of $280 \mathrm{~W}\left(R a_{F}=1.85 \times 10^{14}\right)$ or an imposed temperature difference of $\Delta T=24^{\circ} \mathrm{C}\left(R a=1.55 \times 10^{12}\right)$. The Rayleigh number achieved was large enough for the plume to be turbulent and entrainment is expected to be invariant at still larger Rayleigh numbers. While the Rayleigh number (and therefore a Reynolds number for the plume flow) falls far short of the ocean conditions, the experiments achieve the minimum requirement for dynamic similarity of the convective circulation in the laboratory and ocean.

[13] Experiments were started by applying the thermal forcing and allowing the flow to reach thermal equilibrium (a period of 3 to 4 days, depending on initial and boundary conditions). Thirteen vertical profiles of temperature at 6 locations throughout the tank were taken over a subsequent period of 1 to 2 days. The 13 vertical temperature profiles were averaged to give a single vertical profile from each thermistor. Differences between the 13 profiles were discernible only in the bottom $20 \mathrm{~mm}$ over the heated base, where the thermistors traversed through small-scale convective eddies [Mullarney et al., 2004]. As the aim was to obtain accurate temperature measurements, removal of the sidewall insulation was undesirable and only brief intervals ( $\leq 30 \mathrm{~min}$ ) of flow visualization were carried out. Potassium permanganate crystals were dropped through access tubes in the tank lid and no measurable temperature perturbations 
were seen. In a separate calibration experiment the cooling was turned off, the tank allowed to heat up above the room temperature before the heating was turned off, and the subsequent cooling rate of the tank measured. This gave the heat loss as $1.013 \times\left(T_{\text {tank }}-T_{\text {lab }}\right)$ (in Watts), which implies that between 0.5 and $3.5 \%$ of the total heat input to the tank was lost to the room in the flow experiments. The conductive heat transfer through the barrier forming the sill was calculated for the worst case to be $0.2 \%$ of the total heat input.

\section{Results}

[14] The circulation (e.g., Figure 2) was similar to that in previous observations of horizontal convection with no sill [e.g., Rossby, 1965; Mullarney et al., 2004]. There was a stable thermal boundary layer above the cooled portion of the base. Water in the boundary layer flowed continually from the cooled region of the base to the heated portion, where a convective mixed layer (CML) was maintained. The CML was the result of local convective instabilities on the heated boundary and was capped by the overlying stable boundary layer stratification. For small and moderate sills (i.e. for $R_{D}>0.15$ ), the depth of the CML increased toward the endwall of the tank, at which point all the overlying stratification had been eroded and the CML carried most of the boundary layer transport into an unsteady, buoyant endwall plume which rose into the small basin. The small basin was kept well mixed above the level of the sill (as indicated by temperature profiles, which are not shown here) by the turbulent convection that was free to rise from the base while being swept in a basin-scale overturning. For the largest sills $\left(R_{D} \leq 0.15\right)$, the vertical extent of the CML was instead limited by the warm well-mixed region above the level of the sill. A small fraction of the CML transport, consisting of the warmer water at the top of the stable boundary layer, did not acquire sufficient buoyancy to rise in the plume and was returned above the boundary layer in a weak horizontal intrusion. The horizontal extent of this weak intrusion was steady and finite, and determined by balancing the rates at which intrusion water was being supplied by the plume and recycled into the lower boundary layer. Water was continually displaced from the small basin in a sill overflow that supplied a turbulent plume in the large basin. (In contrast, recall that for cases without a sill and hence no small basin, there was a single plume against the tank endwall) [Mullarney et al., 2004]. Entrainment of ambient water from the large basin into the overflow plume maintained a weak stable density stratification throughout the depth of the large basin. The large-scale circulation was dependent in detail upon the sill geometry, but included the boundary layer flow toward the small heated basin, entrainment into the endwall plume and sill overflow, and a broad downward flow in the large basin toward the forcing boundary.

[15] Temperature data is generally presented here in normalized form, $T_{n}(z)=\left(T(z)-T_{c}\right) / \Delta T$, where $T(z)$ is the temperature measured at depth $z, T_{c}$ is the temperature of the cooled boundary and $\Delta T$ is the temperature difference between the heated and cooled regions of the boundary in the same experiment (measured in the copper base). In the cases of an imposed heat flux, $\Delta T$ was free to adjust to ensure the imposed heat flux was accommodated. The thermal boundary layer thickness $\delta$ is defined here as the region accommodating $98 \%$ of the top-to-bottom temperature difference, based on the two profiles above the cooled region in the large basin. The heat transport can be characterized by the Nusselt number

$$
N u=\frac{F_{T} L}{\rho c_{p} \kappa_{T} \Delta T}
$$

where $F_{T}$ is the average input (and output) of heat per unit area from the heated (cooled) region. However, $F_{T}$ is known only for the experiments with imposed flux boundary conditions (Table 1).

\subsection{The Effect of Sill Depth}

[16] The effect of sill depth in the oceans is the key question of interest. In the experiments, sill depth is represented by the normalized gap height $R_{D}$ and its effect on the circulation is illustrated by Figures 2 and 3 . When the gap was large, no direct interaction is apparent between the sill overflow and the relatively cooler boundary layer flow at the tank base. However, when $R_{D} \lesssim 0.15$, the overflow and the (cooler) boundary layer were forced to interact in the vicinity of the sill. This interaction increased the range of temperatures in the overflow, leading to an increased proportion of overflow water not sufficiently buoyant to be fully incorporated into the plume and rise through the depth of the large basin. It instead formed a weak horizontal intrusion of steady and finite length at the level of the sill; intrusion water was recycled into the lower boundary layer. Thus, the intrusion also introduced an alternate circulation pathway for boundary layer fluid that bypassed the small basin. This pathway is dominant for very small gaps $\left(R_{D} \lesssim\right.$ $0.05)$, for which exchange across the sill was strongly restricted. In this extreme, a larger proportion of the water from the boundary layer was present in the plume that rose through the depth of the large basin (Figures 2c, 2d, and 3c). In the limit where the gap was closed, circulation in the large basin resembled that expected for horizontal convection in a box of reduced length $L_{2}$ and reduced heat input.

[17] The two types of boundary condition gave qualitatively different circulations when the gap was small. For imposed heat flux the sill exchange flow must accommodate a fixed proportion of the heat input (which depends on the lateral position of the sill), whereas there is no constraint on the heat transport for imposed temperature difference. Consequently, the stable boundary layer and sill overflow were confined to more rapidly flowing (and thinner) layers for smaller gap heights with imposed flux conditions (Figure 3 ). With imposed temperature difference, on the other hand, the smaller gap tended to shut off the exchange flow (Figure 2c). Convective instabilities at the heated base then mixed throughout the small basin the small proportion of water that passed through the gap. Note that for imposed temperature difference and $R_{D}=0$ (Figure $2 \mathrm{~d}$ ), there was a weak horizontal intrusion from the base of the plume: a possible explanation for this particular case is that the tank length is effectively shortened and the Rayleigh number reduced 

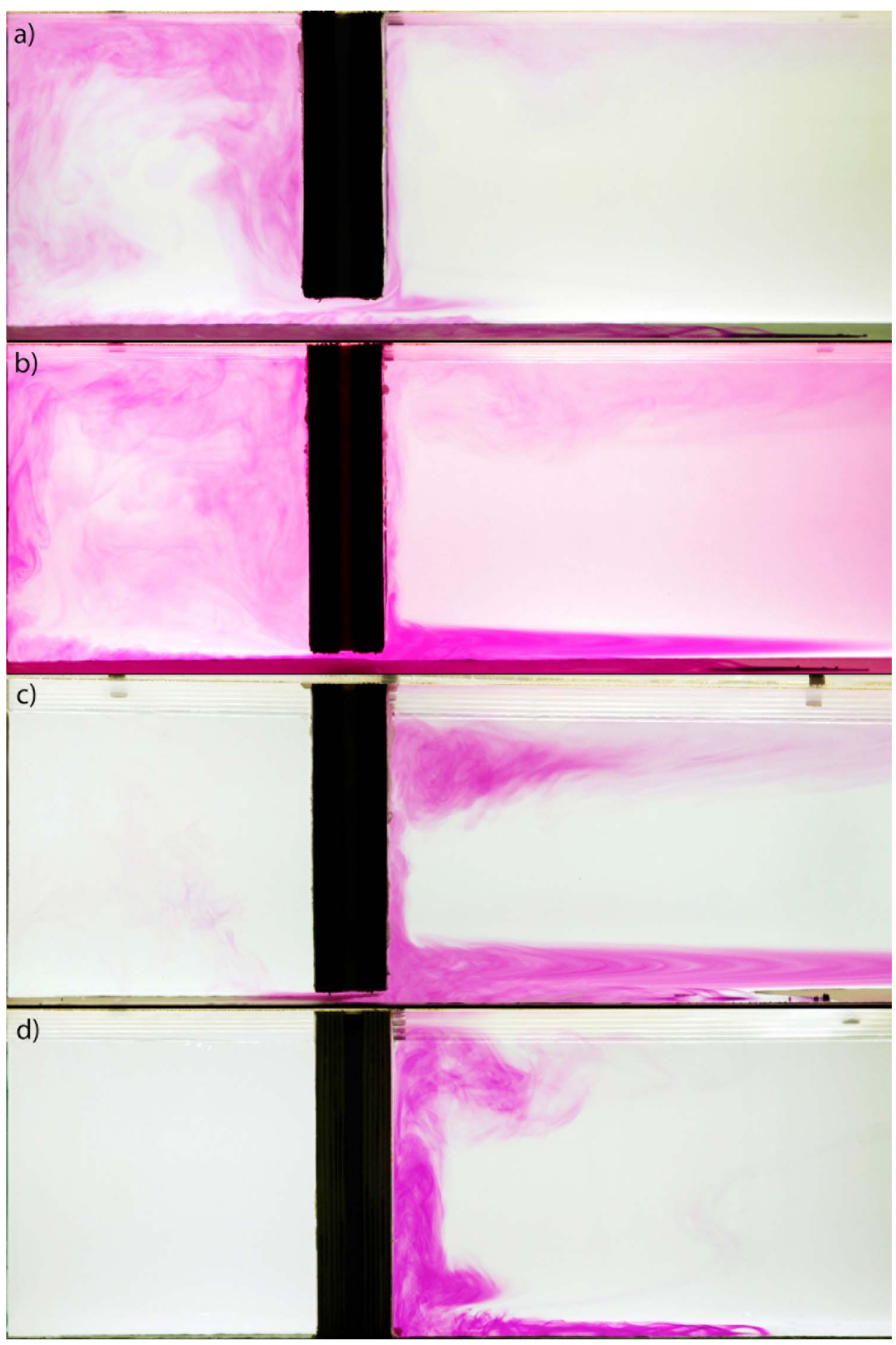

Figure 2. Photos of experiments with an imposed temperature difference and a flat sill for $R_{D}$ values of (a) 0.15 , (b) 0.1 , (c) 0.05 , and (d) 0 . Just over half of the tank is visible: the field of view extends $75 \mathrm{~cm}$ from the left-hand end and incorporates the heated region. Potassium permanganate crystals were dropped into the bottom boundary layer at the midpoint of the box, where they dissolved. The tracer was advected with the flow, beginning with mixing through the convective mixing layer over the heated plate. The weak horizontal intrusions at the sills are visible; in photos they appear prominent due to their steady nature and minimal dilution of the tracer dye, but in reality they do not significantly modify the circulation. 

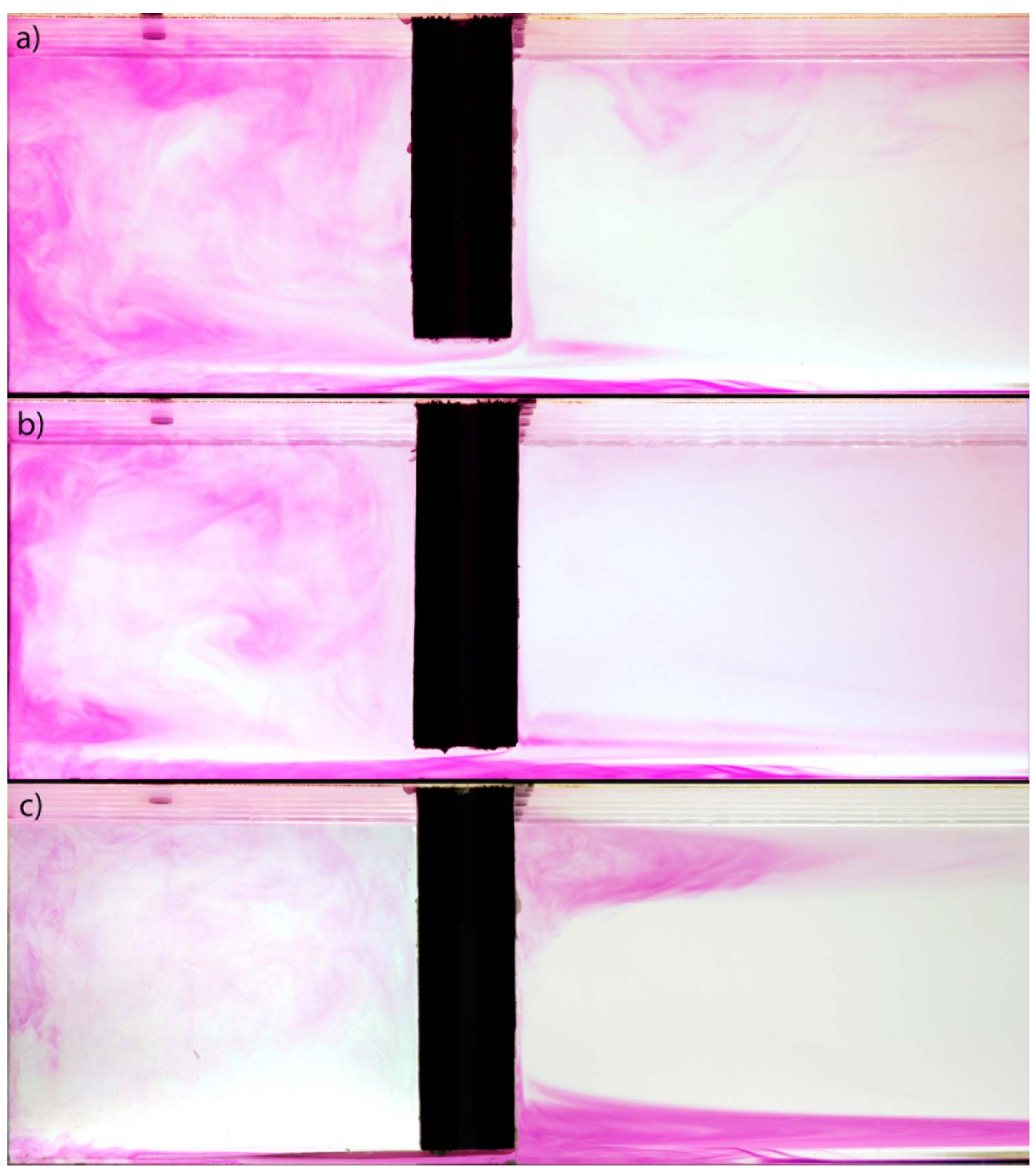

Figure 3. Photos of experiments with an imposed flux and a flat sill with $R_{D}=$ (a) 0.15 , (b) 0.1 , and (c) 0.05. Only the left-hand (heated) half of the tank is shown. Dye tracer was added as in Figure 2.

sufficiently to support the intrusive regime of horizontal convection [Hughes and Griffiths, 2008].

[18] Examples of vertical profiles of normalized temperature $T_{n}(z)$ in the large basin are shown in Figure 4. The profiles show that the temperature field was almost unchanged by the presence of a sill, for a given set of boundary conditions, if the normalized gap height was not small $\left(R_{D} \gtrsim\right.$ $0.15)$. Slight thickening of the thermal boundary layer and warming (toward the temperature of the heated base, $T_{n}=1$ ) in the basin interior was measured as the gap was decreased from $R_{D}=1$ to $R_{D}=0.15$. The effects of the sill depth on interior temperatures and on the difference between the two basins are summarized in Figure 5, where normalized temperatures at middle depth are plotted as a function of gap height. Hughes et al. [2007] predict $T_{n}(D / 2)=0.87$ for the imposed heat flux experiments with no sill, consistent with our results. The temperature difference between the two basins (Figure $5 \mathrm{c}$ ) was very small for $R_{D} \gtrsim 0.15$, a further sign that the sill did not significantly impede the circulation. The thermal boundary layer thickness, plotted in Figure 6, is normalized by that measured for identical boundary conditions in the absence of a sill and is unchanged for $R_{D} \gtrsim 0.2$, or only slightly increased for $0.1 \lesssim R_{D} \lesssim 0.2$.

[19] For $R_{D} \lesssim 0.15$ the presence of a sill resulted in a global modification of the temperature field (Figures 4a, $4 \mathrm{~b}, 5$, and 6). Although the details show some dependence upon boundary conditions, a number of consistent features emerge. As the gap height was decreased below $R_{D}=0.15$, the temperature difference between the two basins increased (Figure $5 \mathrm{c}$ ). This increase follows a warming of the small basin and allows buoyancy forcing to maintain an exchange flow across the sill. For imposed heat flux the exchange must carry (at least) all the heat input from the base of the small basin, and the lateral temperature difference is expected to increase without bound as $R_{D} \rightarrow 0$. (Although not apparent in Figure $5 \mathrm{~b}$ the range of temperatures measured in the large basin increased monotonically as $R_{D}$ decreased for all $R_{D}$.) In contrast, for the case of imposed temperature difference there is no requirement for the exchange to carry a particular amount of heat or mass, and the small basin approached the 

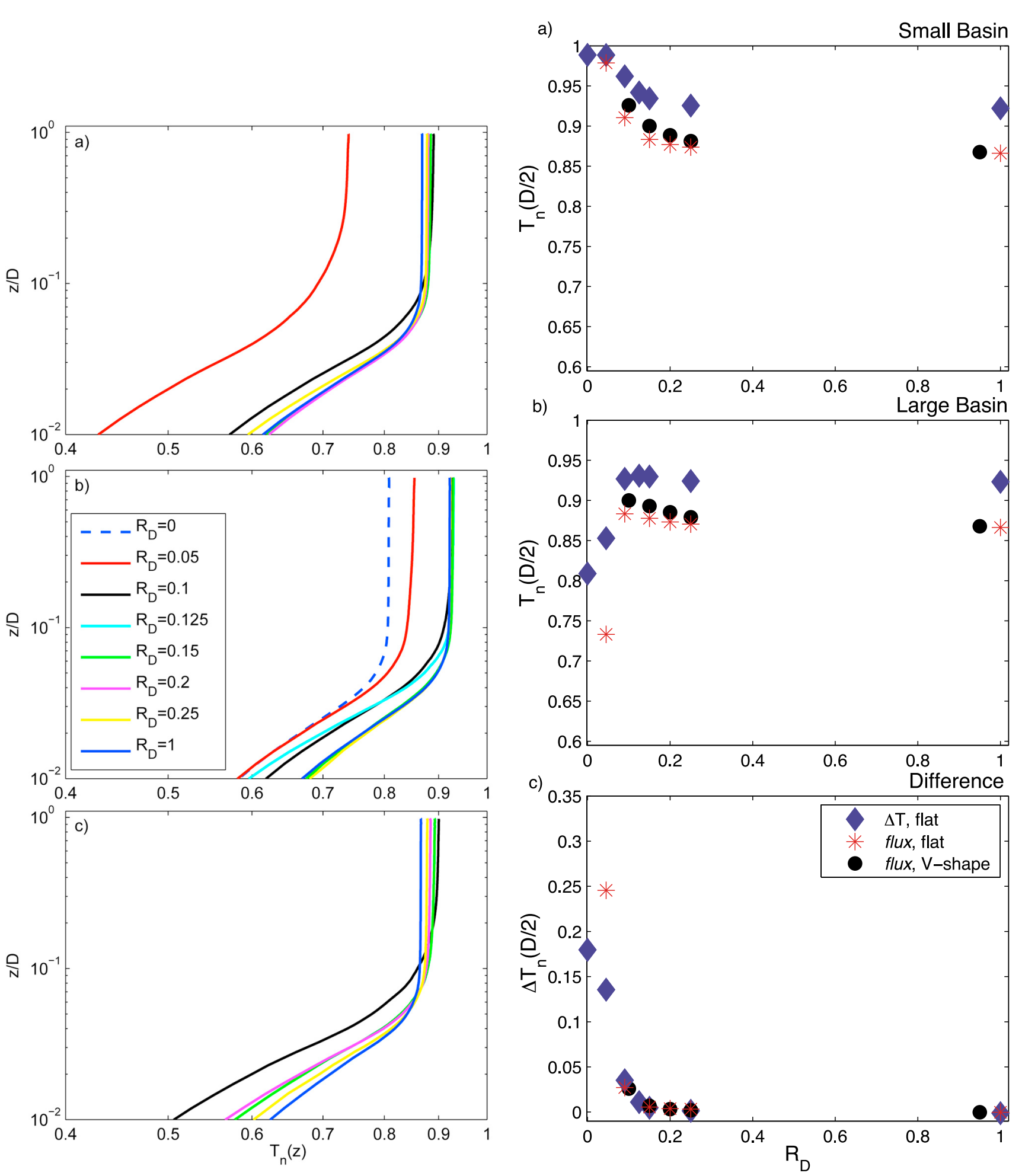

Figure 4. Vertical profiles of normalized temperature, $T_{n}(z)=\left(T(z)-T_{c}\right) /(\Delta T)$, where $T_{c}$ is the temperature measured in the cooled base. Each plotted profile represents an average from two thermistors positioned in the large basin above the cooled plate, where horizontal temperature variations are small. Note that the vertical axis is logarithmic and height is normalized by the total depth: (a) imposed heat flux experiments with a flat sill (1-6), (b) imposed temperature difference experiments with a flat sill (11-17), and (c) experiments with a V-shaped sill (18-22).

Figure 5. Normalized temperatures $T_{n}$ at middle depth in the (a) small basin and (b) large basin, and (c) the normalized temperature difference $\Delta T_{n}$ between the two basins, where $T_{n}(D / 2)=\left(T(D / 2)-T_{c}\right) /(\Delta T)$ : diamond, imposed temperature difference and flat sill; star, imposed heat flux and flat sill; solid circle, imposed heat flux and V-shaped sill. For imposed heat flux with $R_{D} \rightarrow 0, T_{n}(D / 2)$ in the small and large basins will approach the limits of 1 and 0 , respectively (recall that $\Delta T$ will however continue to increase), and thus $\Delta T_{n}(D / 2)$ will approach 1 . 


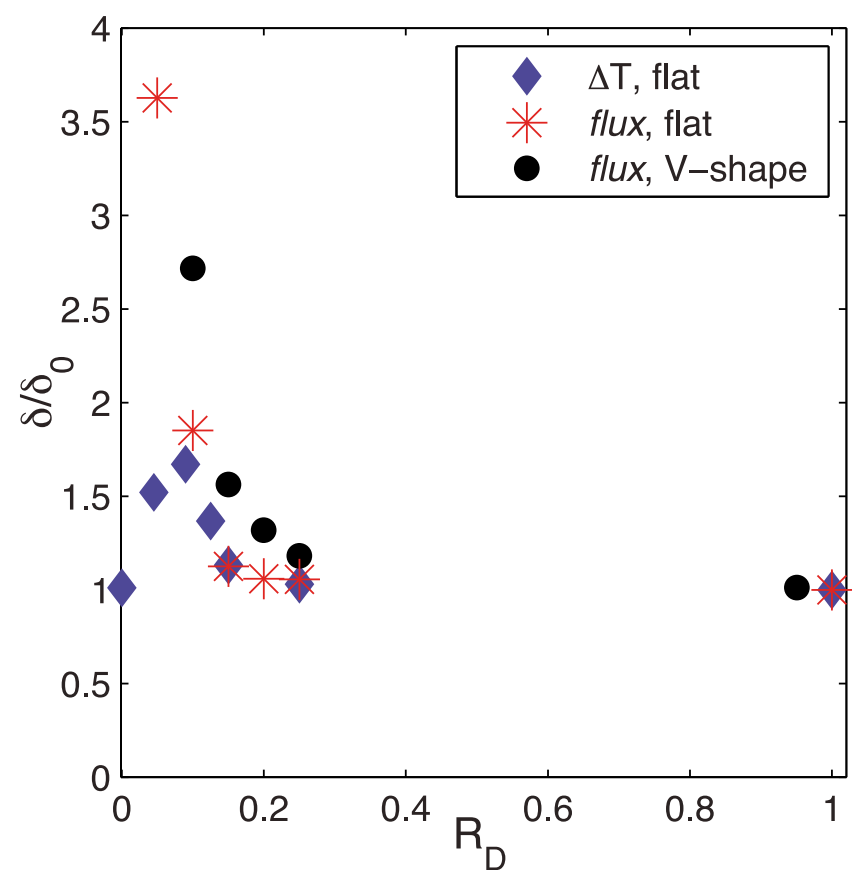

Figure 6. Normalized thermal boundary layer thickness $\delta / \delta_{0}$ as a function of normalized gap height $R_{D}=(D-$ $\left.D_{S}\right) / D$ for flat and $\mathrm{V}$-shaped sills. Data are for boundary conditions of imposed heat flux (star) and imposed temperature difference (diamond) with a flat sill, and for imposed heat flux with a V-shaped sill (solid circle). The normalization is in each case based on the boundary layer thickness $\delta_{0}$ measured in control cases having identical boundary conditions but no sill.

boundary temperature. The large basin too was relatively warmer for $0.1 \leq R_{D} \leq 0.2$, but by a lesser amount, whereas for $R_{D} \lesssim 0.1$ there was a sharp drop in the normalized temperature of the large basin (Figures $4 \mathrm{~b}$ and $5 \mathrm{~b}$; the range of temperatures in the large basin also begins to decrease below very small values of $R_{D}$ ). For the case of an imposed heat flux this sharp decrease can be partially attributed to an increase in $\Delta T$ resulting from the restriction of mass and heat transport across the sill.

[20] The modification of the temperature field for small gaps is also evident in the boundary layer thickness $\delta$, which we compare to the thickness $\delta_{0}$ under identical surface boundary conditions but without the sill (Figure 6). For $R_{D} \leq 0.2$, the boundary layer was thicker. We attribute this to the formation of the strong horizontal intrusion near the level of the sill (Figures 2 and 3), which coincides with a reduction of heat removed from the box by conduction to the cooled boundary for imposed temperature difference and with an increased temperature difference across the boundary layer for imposed heat flux. However, for dimensionless gap heights $R_{D} \lesssim 0.1$, the boundary layer thickness was more strongly dependent upon the boundary conditions. For imposed temperature difference it thinned from a maximum at $R_{D} \approx 0.1$ as the gap was closed, due to the reduction of heat throughput ( $\delta$ decreases toward a value slightly greater than $\delta_{0}$ as $R_{D}$ approaches 0 ). For imposed heat flux no boundary layer thinning was measured at $R_{D} \geq 0.05$ as the heat throughput remained fixed (although it is again expected that $\delta$ will decrease to a value slightly greater than $\delta_{0}$ as $R_{D}$ approaches 0 ).

[21] The variation of Nusselt number with dimensionless gap size is plotted in Figure 7 for the imposed heat flux experiments. The increase in $\Delta T$ as $R_{D}$ decreased below 0.2 (with heat input held constant) led to a monotonic reduction in Nusselt number with decreasing gap size (Figure 7). The Nusselt number is expected to decrease to 0 as $R_{D} \rightarrow 0$, based on the unbounded increase in base plate temperature difference for $R_{D} \rightarrow 0$.

[22] Four additional experiments (7-10 in Table 1) were conducted at two other imposed heat fluxes, 210 and $420 \mathrm{~W}$, for $R_{D}=0.1$ and 1 . The results were similar to those with an imposed heat flux of $280 \mathrm{~W}$, although measurements indicated that the sill had a relatively greater effect on the temperature field for smaller imposed heat fluxes. This behavior can be attributed to a thicker boundary layer for smaller Rayleigh numbers [Rossby, 1965; Mullarney et al., 2004], and we return to these results in section 4 .

\subsection{Nonuniform Sills}

[23] Cross-stream variation in the sill height caused the overflow to be concentrated in the vicinity of the maximum sill gap, at the centerline of the tank. These V-shaped sills (18-22 in Table 1) presented only a small obstruction to the flow close to the tank base, where the boundary layer flows into the small basin, but a much greater obstruction (in terms of the cross-sectional area) at the heights where the sill overflow is exiting the small basin. For most gap heights $\left(R_{D}>0.1\right)$ the overflow carried sufficient horizontal momentum to cause the buoyant plume to separate from the vertical side of the sill, subsequently rising through the large basin at an angle of $\sim 30^{\circ}$ to the vertical (Figure 8). The separated plume was initially laminar but unsteadiness and turbulence developed as it rose. This separation behavior

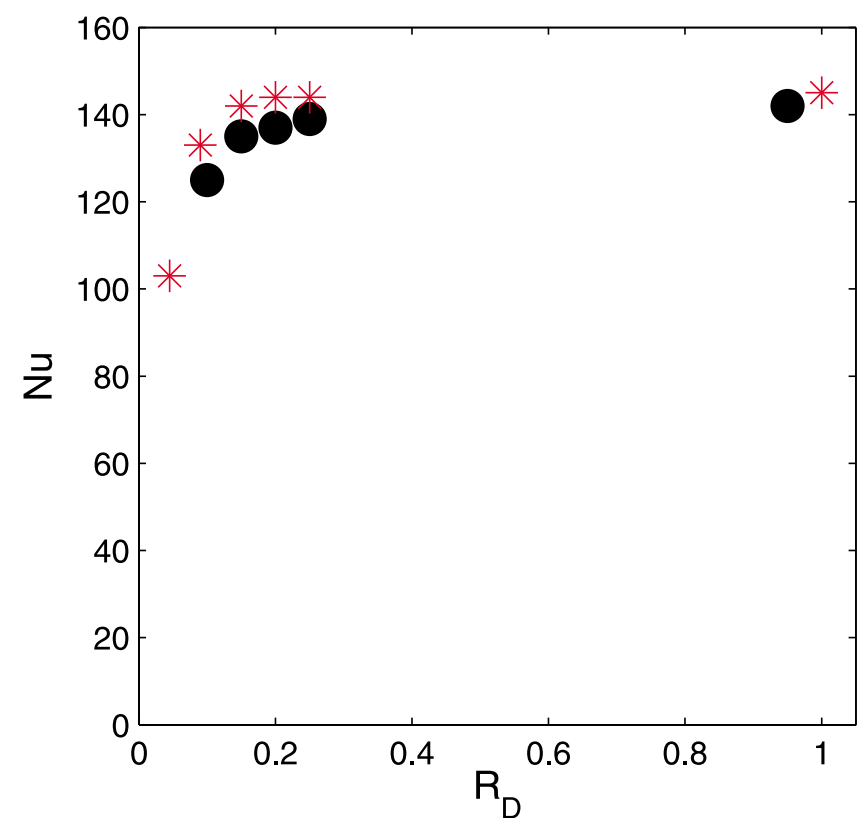

Figure 7. Nusselt numbers for the experiments with an imposed heat flux of $280 \mathrm{~W}$ and flat (star) and V-shaped sills (solid circles). 


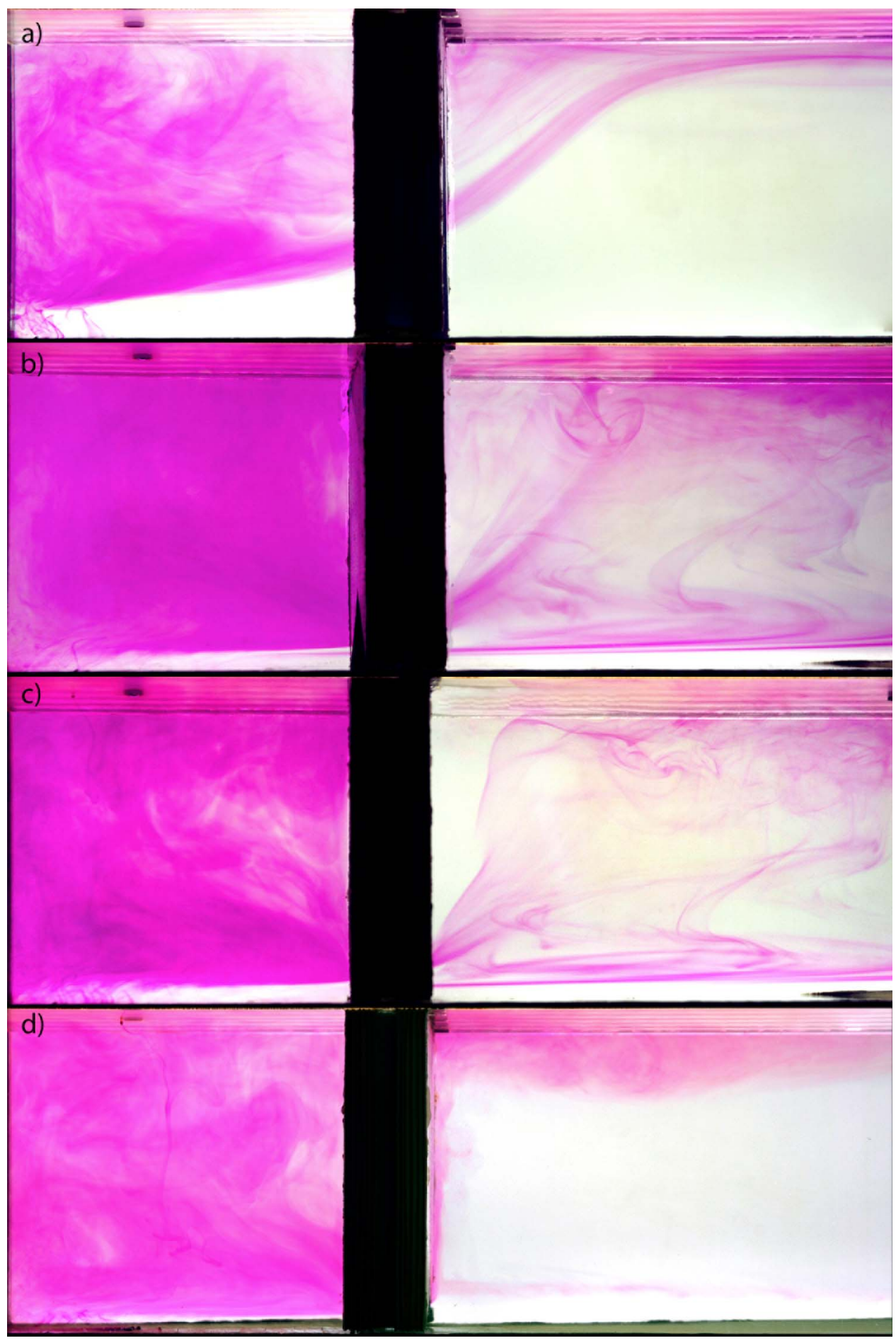

Figure 8. Photographs of experiments with an imposed heat flux and a V-shaped sill with $R_{D}=($ a) 0.95 , (b) 0.2 , (c) 0.15 , and (d) 0.1 . Only the left-hand (heated) half of the tank is shown. Potassium permanganate crystals were dropped into the bottom boundary layer in the small basin on the left.

in the laboratory is attributed to greater momentum of the relatively narrow overflow through the apex of the $\mathrm{V}$-shaped gap compared with the uniform overflows for flat sills, and is therefore also a result of the vertical sides of the sill and is unrealistic in the ocean context. However, the experiments offer useful insight into relevant flow dynamics associated with entrainment into the plume. For the largest gap examined $\left(R_{D}=0.95\right)$ the overflow plume reached the top prior to the onset of unsteadiness. For the smallest gap $\left(R_{D}=0.1\right)$ the overflow remained attached to the side of the sill (Figure 8d). Otherwise, the circulation details were almost identical to those observed with a flat sill and the same gap. 
[24] The shape of the sill led to only minor changes in the temperature field. Normalized temperature profiles in the large basin (Figures $4 \mathrm{a}$ and $4 \mathrm{c}$ ) and for a given $R_{D}$ show that the temperature throughout the flow is slightly warmer with a V-shaped sill (see also Figures 5a and 5b). Crossstream variation of the sill height also resulted in a larger boundary layer thickness for a given $R_{D}$ (Figure 6), which we suggest is due to blocking of the boundary layer and return flow by the sill geometry. The increased boundary layer thickness is consistent with the slight warming in the interior of the large basin, thus maintaining the temperature gradient in the boundary layer for conduction to the cooled plate to accommodate the imposed heat throughput in the flow. The increased temperature difference also implies a smaller Nusselt number $N u$ than for a flat sill with the same maximum gap height (Figure 7). Note however that the temperature difference across the sill was independent of sill shape (Figure 5c). Hence the interior buoyancy difference driving the exchange flow is determined primarily by the maximum gap height.

\subsection{Effects of Sill Position}

[25] An additional eight experiments (23-30 in Table 1) were carried out to investigate the effect of lateral sill position; the basin length ratio was changed from $L_{1} / L_{2}=$ $1 / 4$ to 1 and 4 for both types of boundary conditions, with flat sills having $R_{D}=0.05$ and 0.15 . The position of the sill played only a minor role in all experiments with $R_{D}=$ 0.15 and no significant differences were measured. However, the position of the sill had a significant influence on the circulation for the smaller gap height $\left(R_{D}=0.05\right)$ with both types of boundary conditions. For $L_{1} / L_{2}=1$ and 4 the basin to the right of the sill (no longer the larger basin, but cooled by the base) contained an overturning circulation that was largely confined to the lower $1 / 5$ to $1 / 3$ of the tank. This shallow overturning was attributed to the large temperature range of water feeding the sill overflow from the left-hand basin, which for these sill positions had a stratified thermocline overlapping the depth of the sill. The exchange flow across the sill in these cases was minimal, except for the case of $L_{1} / L_{2}=1$ and an imposed heat flux in which the exchange must accommodate all the heat transport. The circulation in the left-hand basin (which was bounded below by all the heated base) resembled that of standard horizontal convection, with the exception of the experiment with an imposed temperature difference for $L_{1} / L_{2}=1$. In this exceptional case, the absence of any differential heating in either basin, coupled with the restriction presented by the sill, means that there is little reinforcement of a large-scale overturning. Instead of the boundary layer feeding into an endwall plume, convection was observed above the thermal boundary layer throughout much of the left-hand basin.

\section{Discussion}

[26] The results show that the influence of a sill on the basin-scale circulation becomes especially strong when the stable boundary layer flow interacts directly with the sill overflow, tending to reduce the buoyancy of the sill plume and modify the range of densities in the large basin. We therefore define $R_{0}=\left(D-D_{S}\right) / \delta_{0}=R_{D}\left(D / \delta_{0}\right)$, where $\delta_{0}$ is the boundary layer thickness in corresponding control cases having the same boundary conditions but no sill. Thus the ratio of the gap height and boundary layer thickness is an important parameter. Given that the boundary layer and the counterflowing overflow at the crest of the sill are of similar thickness, we anticipate that $R_{0} \lesssim 2$ implies an interaction that impedes the sill exchange flow, modifies the boundary layer thickness from the control case and leads to mixing that modifies the overall circulation. Note that as the boundary layer thickness $\delta_{0}$ is a function of Rayleigh number $\left(\delta_{0} \sim R a_{F}^{-1 / 6}\right)$ [Mullarney et al., 2004], we might expect a given sill to pose less of an obstacle to flow for larger Rayleigh numbers. This is indeed apparent in Figures 9c and 10 (triangle symbols, imposed flux increasing to the right), where an increased imposed flux returns a decreased interbasin normalized temperature difference and normalized boundary layer thickness.

[27] The data from Figures 5 and 6 are replotted as a function of $R_{0}$ in Figures 9 and 10, respectively, together with the additional data from experiments in which $R a_{F}$ was varied. The normalization largely collapses all the temperature data in Figure 9 for $R_{0} \gtrsim 1$, irrespective of sill geometry, though a small difference between imposed temperature and imposed flux boundary conditions (Figures 9a and $9 \mathrm{~b}$ ) is apparent. The normalized boundary layer thickness (Figure 10) similarly collapses for $R_{0} \gtrsim 1$, again with a small dependence on the boundary conditions. Importantly, Figures 9 and 10 show that the influence of a sill on the circulation is apparent for $2 \lesssim R_{0} \lesssim 4$, and strong for $R_{0}<2$. A significant dependence on the boundary conditions develops for $R_{0}<2$.

[28] Partial blocking of the boundary layer flow by the sill alters the temperature stratification in the large basin (see Figure 4) and shifts the normalized temperature at middle depth in the large basin closer to that of the cooled boundary (Figure 9b; note that this corresponds to an increased range of temperatures, except for imposed temperature difference at very small $R_{0}$ ). The normalized temperature at middle depth in the small basin approaches that of the heated boundary for large sills $\left(R_{0} \rightarrow 0\right.$, Figure 9a). Larger temperature differences are required to drive the exchange flow across larger sills (smaller $R_{0}$; Figure 9c), causing the water entering the overflow plume in the large basin to be more buoyant. As the overflow is the source of the most buoyant water in the large basin, the range of temperatures (and therefore the deep stratification) in that basin is increased. The restriction of the sill exchange also results in an intrusion into the large basin at levels comparable with the sill, and the intrusion results in a thicker thermal boundary layer (as measured on the basis of a vertical temperature profile).

\section{Application}

[29] Transformation of surface waters into what eventually becomes North Atlantic Deep Water (NADW) occurs in the Labrador and Nordic Seas [Hansen et al., 2004]. The outflow of dense water from the Nordic Seas must overcome the Greenland-Scotland Ridge (GSR), but no equivalent topographic feature exists in the Labrador Sea. The two main paths that the dense waters take across the GSR are the Denmark Strait (DS) and the Faroe Bank Channel (FBC) (Figure 11), at 620 and $840 \mathrm{~m}$ depth, respectively [Saunders, 2001]. These channels might be crudely approx- 

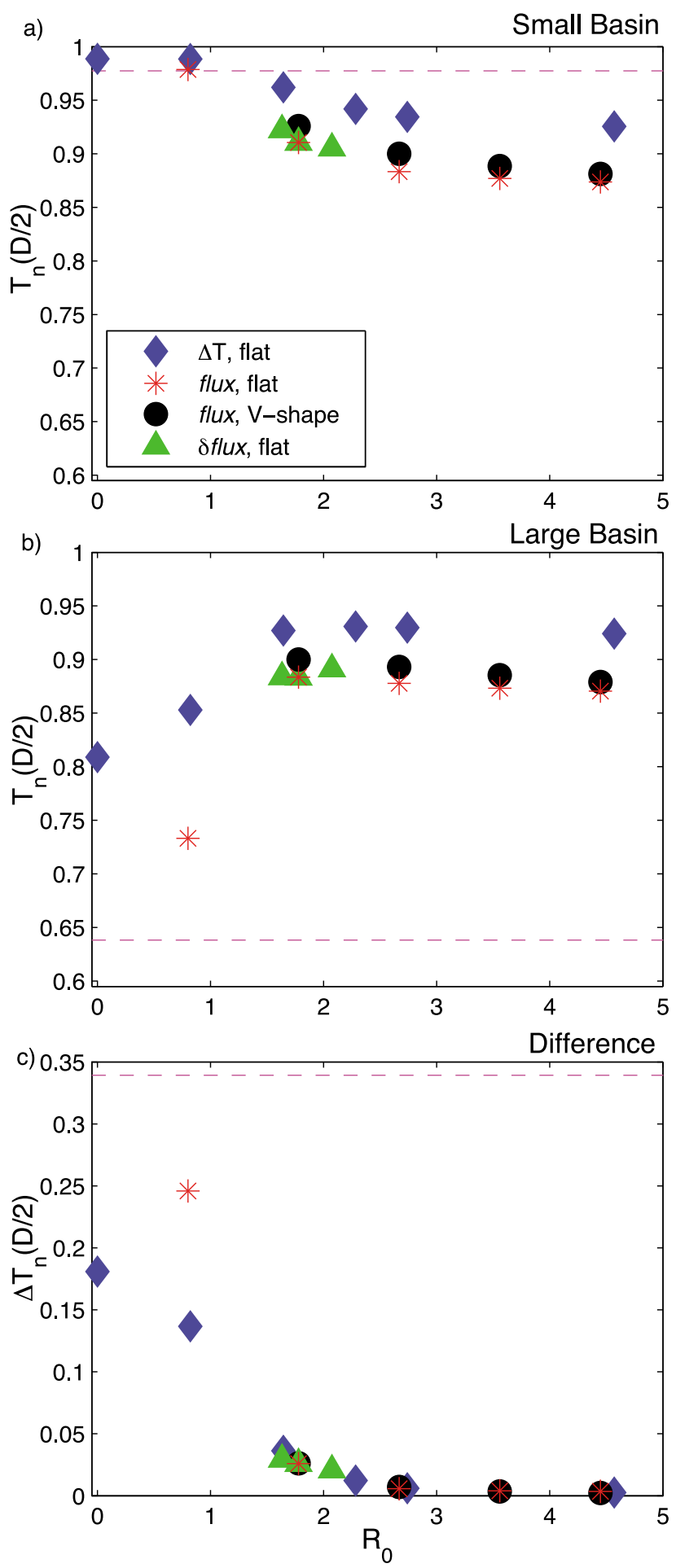

Figure 9. Normalized temperature and temperature difference $\Delta T_{n}$ between the two basins at middle depth as a function of the ratio of gap height to reference boundary layer thickness in the absence of a sill: Experiments with a flat sill and an imposed flux of $280 \mathrm{~W}$ (stars); a range of imposed fluxes (triangles, inputs of 210, 280 and $420 \mathrm{~W}$, increasing to the right); an imposed temperature difference (diamonds); and with a V-shaped sill and imposed heat flux (circles). The North Atlantic observations of Figure 12 are plotted as magenta dashed lines; the method for calculating the position of the lines is described in section 5 . imated as $\mathrm{V}$-shaped sills having $R_{D} \approx 0.15$ and 0.2 , respectively (taking the North Atlantic Ocean as $4000 \mathrm{~m}$ deep). The base of the thermocline in the North Atlantic is found at a depth $(\delta)$ of approximately $1000 \mathrm{~m}$. We are unable to specify the exact depth the thermocline would take in the absence of topography $\left(\delta_{0}\right)$. However, a value for $\delta_{0}$ in excess of $400 \mathrm{~m}$ at the latitude of the GSR characterizes the overflows by dimensionless gap heights $R_{0}<2$ and offers consistency with observations. Otherwise alternative mechanisms to substantially increase the thermocline depth to match observations would be required. Thus the experimental results imply that these sills have an ocean-wide effect on the thermocline depth and circulation. A more verifiable prediction from the experimental results is that the restriction of the circulation results in significant modification of the dense overflow plume waters by interaction with thermocline waters in the vicinity of the GSR. As outlined below, this prediction is consistent with observations.

[30] The Labrador and Nordic Seas each account for approximately $1 / 3$ of the total transport of NADW flowing south in the North Atlantic [Hansen et al., 2004]. Entrainment of ambient water into the GSR overflow plumes contributes the final third of the total production rate of NADW. This entrainment doubles the GSR overflow transport [Dickson and Brown, 1994] and significantly modifies the properties of the sinking plumes. Our experiments demonstrate how the modification depends on whether the overflow plume originates at depths shallow enough for it to interact with the thermocline. In the case of the Denmark Strait Over-



Figure 10. Normalized thermal boundary layer thickness $\delta / \delta_{0}$ as a function of $R_{0}$ for flat and V-shaped sills. Symbols as defined in Figure 9. The red dashed line represents the theoretical boundary layer thickness for $R_{D}=0$ and an imposed heat flux (allowing a 50\% smaller heat flux and a $25 \%$ shorter box length available to the circulation owing to the closure of the sill passage); thus a maximum of $\delta / \delta_{0}$ exists in the range $0<R_{D}<0.05$. 


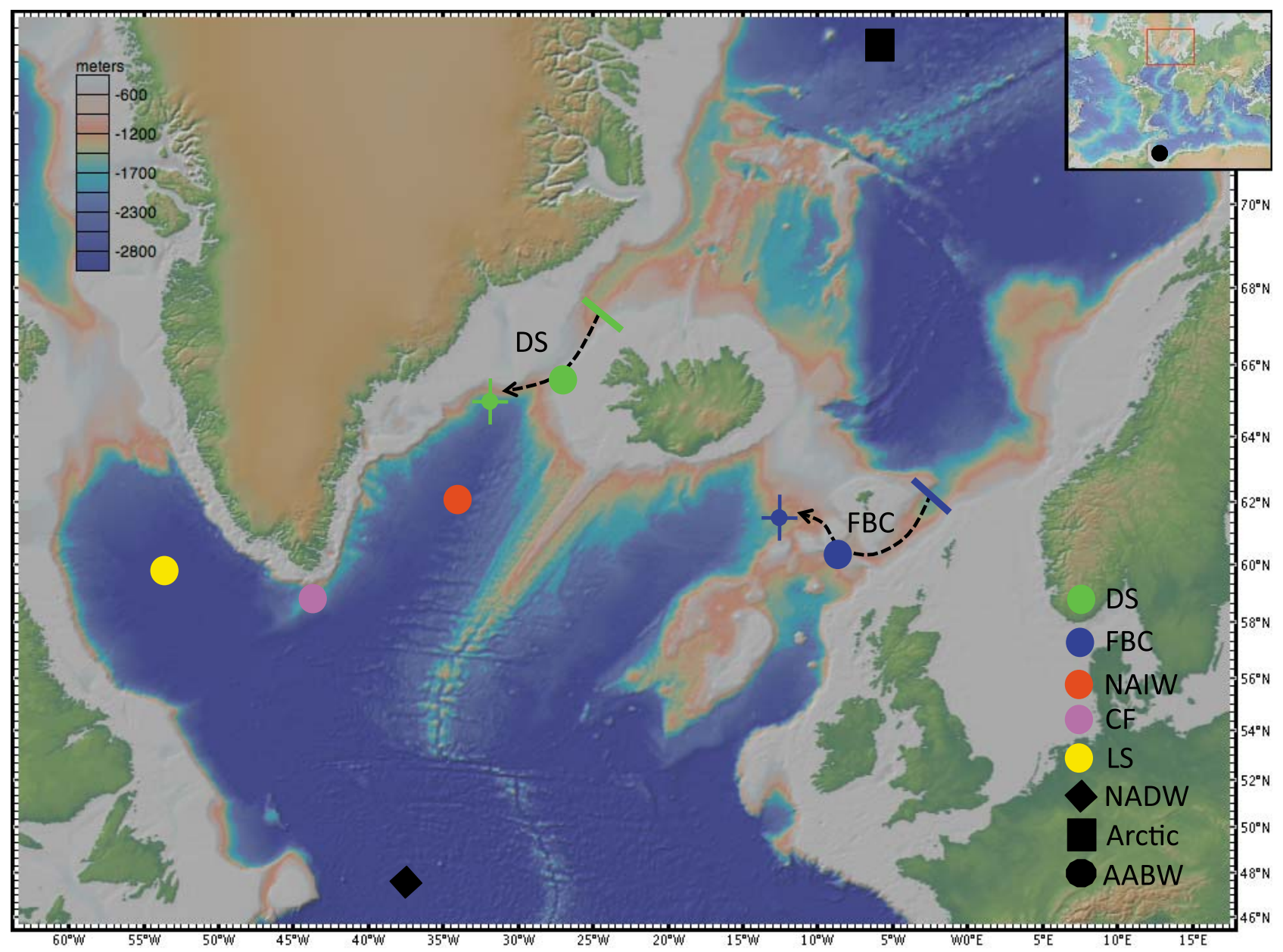

Figure 11. Schematic of Denmark Strait Overflow (green) and Faroe Bank Channel Overflow (blue) pathways across the Greenland-Scotland Ridge. The locations of the water properties used to generate Figure 12 are shown; the green and blue bars and cross-haired circles show the overflow source and outflow locations, respectively. Figure 11 was generated in GeoMapApp utilizing the Global MultiResolution Topography synthesis of Ryan et al. [2009].

flow (DSO) the plume has a maximal warming rate of 0.4 to $0.5^{\circ} \mathrm{C}$ per $100 \mathrm{~km}$ during the first $200 \mathrm{~km}$ downstream of the sill (where the bulk of the slope plume descends through the thermocline), and a decreased warming rate of $0.05-0.1^{\circ} \mathrm{C}$ per $100 \mathrm{~km}$ for the remainder of the descent before reaching Cape Farewell [Voet and Quadfasel, 2010]. The Faroe Bank Channel Overflow (FBCO) undergoes intense mixing with overlying thermocline waters within the FBC, diluting the entire FBCO [Fer et al., 2010]. Once the FBCO plume has exited the FBC and sunk below a depth of $1200 \mathrm{~m}$, the rate of change, with downstream distance, of the outflow plume properties is much reduced in potential temperature-salinity $(\theta-S)$ space; Mauritzen et al. [2005] attribute this to the overflow no longer encountering and entraining thermocline waters. In addition, mixing rates for the GSR overflows have been found from hydrographic data to be 10 times higher than further downstream (and 100 times greater than the background mixing rate) [Lauderdale et al., 2008].

[31] Figure 12 shows the range of $\theta-S$ properties that characterize the dense southward flowing waters entering the DS and FBC (green and blue thick bars, respectively), where mixing proceeds (in the region bounded by the green and blue broken lines) with the overlying, much warmer and saltier thermocline waters (large green and blue circles). The properties of these mixed waters, which then sink beyond the thermocline depths, are shown by the small green and blue circles. The temperature and salinity of the overflows are increased by approximately $1^{\circ} \mathrm{C}$ and $0.1 \mathrm{psu}$ during this stage due to the interaction with thermocline waters. At greater depths the overflow plumes entrain North Atlantic intermediate water (red circle), which causes a relatively small modification of the overflow properties (in the region bounded by magenta broken lines), before forming the deep western boundary current that rounds Cape Farewell (magenta circle) at depths of 1900-3000 m and enters the Labrador Sea (yellow circle). The waters from the GSR overflow plumes then interact with waters in the Labrador Sea before exiting as NADW (black diamond). Thus the increase in temperature and salinity during the transformation from GSR source waters to NADW is seen to occur almost exclusively in the GSR overflows, with most of this change occurring as a result of interaction with the thermocline waters. 


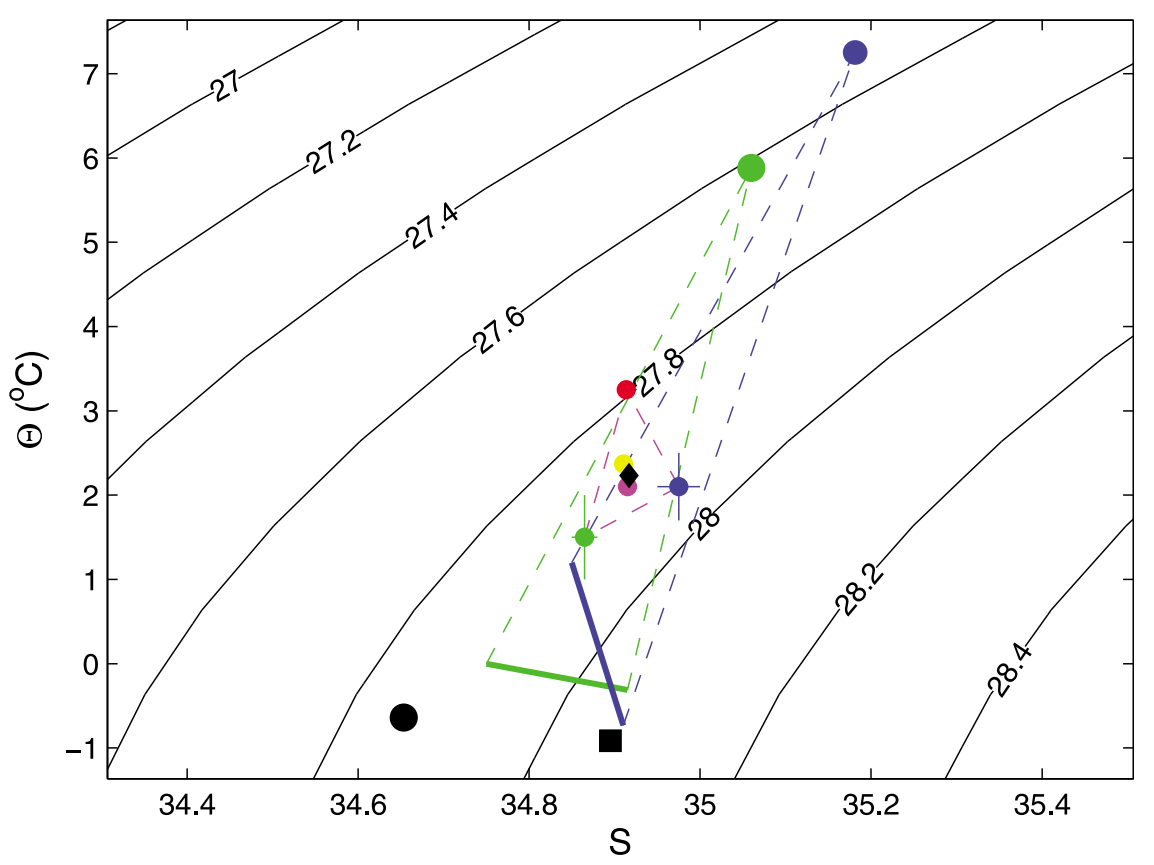

Figure 12. Characteristic potential temperature-salinity $(\theta-S)$ diagram for the water masses involved in the Greenland-Scotland Ridge exchange. The water mass properties [from Saunders, 2001; Locarnini et al., 2010; Antonov et al., 2010] are the dense southward flowing waters entering the Denmark Strait and Faroe Bank Channel (green and blue bars, respectively), the relatively warmer and saltier overlying thermocline waters (large green and blue circles, respectively), and the overflow plumes sinking beyond the thermocline depths (cross-haired green and blue circles, respectively). These overflow plumes entrain North Atlantic intermediate waters (red circle) to give the deep western boundary current rounding Cape Farewell (magenta circle) and entering the Labrador Sea (yellow circle), subsequently exiting as North Atlantic Deep Water (black diamond). The dashed lines indicate mixing triangles colored as per their respective product waters. Antarctic Bottom Water and Arctic Water are shown by the black circle and square, respectively.

[32] The properties of Antarctic Bottom Water and Arctic Ocean Water are included in Figure 12 (black circle and square, respectively); while Arctic Ocean Water (the ultimate source water for the GSR overflows) is significantly denser than AABW, the NADW is less dense and overlies AABW. This raises the question of what role the GSR might play in influencing the relative densities of AABW and NADW. The experimental results show that the presence of a sill increases the density difference between basins (regardless of surface boundary conditions) and we expect to see the greatest response in the density of abyssal waters in the main (lower-latitude) basin: NADW will be warmer (assuming temperature is the main player in density) than with a small (or no) sill. The experiments also show that the range of temperatures (i.e. strength of the stratification) in the main basin is increased by a significant sill, implying that the GSR causes North Atlantic surface waters to be warmer. This adds to the global influence of the GSR.

[33] Other oceanographic observations lend support to the hypothesis that the GSR has a global influence. In Figure 9 key potential densities (shown by dashed horizontal lines as we lack a robust measure of $R_{0}$ for the GSR) are normalized in the same manner as the experimental data: these are the potential densities of the Arctic Ocean (>2000 m deep) and upper North Atlantic water immediately south of the GSR, which are representative of the range of densities that interact in the vicinity of the sill, as well as the potential densities of the southward flowing waters entering the GSR and the NADW. If the GSR were to have little influence on the circulation, we would expect the normalized middle-depth density (Figures 9a and 9b) to be approximately $87 \%$ of the normalized density range [see Hughes et al., 2007] and to have negligible density difference across the sill (Figure 9c). This is clearly not the case, indicating that the GSR leads to a decrease in the potential density of the NADW (and an accompanying small increase in the potential density of the high-latitude waters). This represents a major influence on the density structure of the ocean.

\section{Conclusions}

[34] The effect of a topographic sill on the convective circulation forced in a model rectangular basin by a meridional gradient of surface heating has been investigated. Various sill sizes, shapes and surface boundary conditions have been examined, yielding a robust set of principles and insights for the large-scale overturning circulation in ocean basins. By convention, the sill is assumed to divide the model ocean into a small (high-latitude) basin, in which a sinking plume is situated, and a main (lower latitude) basin.

[35] The presence of a sill interrupts the large-scale overturning circulation in the model. Nevertheless, a sill 
overflow of relatively dense water from the small to the large basin feeds a plume that maintains a large-scale overturning throughout the main basin (and extending into the small basin at depths above the sill) that is otherwise qualitatively similar to that throughout the domain in the absence of any sill. Indeed, laboratory measurements show that a sill has little dynamical effect on the density structure if the sill top and the surface thermal boundary layer (or thermocline) are separated vertically.

[36] The overturning circulation in the laboratory experiments was found to be strongly restricted when the sill is large enough to ensure the overflow interacts directly with the thermocline. The water in the small basin is well mixed and close to the densest in the entire model ocean. Entrainment of relatively warm water from the thermocline into the sill overflow affects both the bulk density and the density structure in the main basin. In general, the density of abyssal waters in that basin is reduced while the range of densities is increased (relative to a case of no sill), leading to a stronger density stratification.

[37] The results have been applied to the exchange of North Atlantic waters across the Greenland-Scotland Ridge and the formation of NADW associated with these overflows. We find clear evidence of entrained thermocline waters in the NADW that is consistent with a strong role for these topographic sills in the basin-scale circulation. The topographic constriction of these sills leads to NADW that is warmer than it would be if the sills were absent, and to surface waters that are warmed by an even greater degree. Further reasoning has suggested that the GreenlandScotland Ridge could lead to the modification of water properties on a global scale because of the interaction of NADW and AABW. It seems likely that feedbacks involving a modification of the surface circulation and buoyancy fluxes are an important part of this process.

[38] Acknowledgments. This work benefited from support from the Australian Research Council (DP1094542), and we thank A. Beasley for construction of laboratory apparatus.

\section{References}

Antonov, J. I., D. Seidov, T. P. Boyer, R. A. Locarnini, A. V. Mishonov, H. E. Garcia, O. K. Baranova, M. M. Zweng, and D. R. Johnson (2010), World Ocean Atlas 2009, vol. 2, Salinity, NOAA Atlas NESDIS, vol. 69, edited by S. Levitus, 184 pp., NOAA, Silver Spring, Md.

Bryan, F. (1987), Parameter sensitivity of primitive equation ocean general circulation models, J. Phys. Oceanogr., 17, 970-985.

Bryan, K., and M. Cox (1967), A numerical investigation of oceanic general circulation, Tellus, 19, 54-80.

Bryden, H. L., and A. J. G. Nurser (2003), Effects of strait mixing on ocean stratification, J. Phys. Oceanogr., 33, 1870-1872.

Bryden, H. L., J. Candela, and T. H. Kinder (1994), Exchange through the Strait of Gibraltar, Prog. Oceanogr., 33, 201-248.

Cenedese, C., and C. Adduce (2010), A new parameterization for entrainment in overflows, J. Phys. Oceanogr., 40, 1835-1850, doi:10.1175/ 2010JPO4374.1.

Danabasoglu, G., W. G. Large, and B. P. Briegleb (2010), Climate impacts of parameterized Nordic Sea overflows, J. Geophys. Res., 115, C11005, doi:10.1029/2010JC006243.

Dickson, R. R., and J. Brown (1994), The production of North Atlantic Deep Water: Sources, rates and pathways, J. Geophys. Res., 99(C6), 12,319-12,341.

Fer, I., G. Voet, K. Seim, B. Rudels, and K. Latarius (2010), Intense mixing of the Faroe Bank Channel overflow, Geophys. Res. Lett., 37, L02604, doi:10.1029/2009GL041924.
Finnigan, T. D., and G. N. Ivey (1999), Submaximal exchange between a convectively forced basin and a large reservoir, J. Fluid Mech., 378 , $357-378$.

Finnigan, T. D., and G. N. Ivey (2000), Convectively driven exchange flow in a stratified sill-enclosed basin, J. Fluid Mech., 418, 313-338.

Finnigan, T. D., K. B. Winters, and G. N. Ivey (2001), Response characteristics of a buoyancy-driven sea, J. Phys. Oceanogr., 31, 2721-2736.

Hansen, B., and S. Østerhus (2007), Faroe Bank Channel overflow 1995-2005, Prog. Oceanogr., 75, 817-856.

Hansen, B., S. Østerhus, D. Quadfasel, and W. Turrell (2004), Already the day after tomorrow?, Science, 305, 953-954.

Hughes, G. O., and R. W. Griffiths (2006), A simple convective model of the global overturning circulation, including effects of entrainment into sinking regions, Ocean Modell., 12, 46-79.

Hughes, G. O., and R. W. Griffiths (2008), Horizontal convection, Annu. Rev. Fluid Mech., 40, 185-208.

Hughes, G. O., R. W. Griffiths, J. C. Mullarney, and W. H. Peterson (2007), A theoretical model for horizontal convection at high Rayleigh number, J. Fluid Mech., 581, 251-276.

Killworth, P. (1995), Hydraulic control and maximal flow in rotating stratified hydraulics, Deep Sea Res., Part I, 42, 859-871.

Lauderdale, J., S. Bacon, A. Naveira Garabato, and P. Holliday (2008), Intensified turbulent mixing in the boundary current system of southern Greenland, Geophys. Res. Lett., 35, L04611, doi:10.1029/2007GL032785.

Legg, S., et al. (2009), Improving oceanic overflow representation in climate models: The Gravity Current Entrainment Climate Process Team, Bull. Am. Meteorol. Soc., 90, 657-670.

Locarnini, R. A., A. V. Mishonov, J. I. Antonov, T. P. Boyer, H. E. Garcia, O. K. Baranova, M. M. Zweng, and D. R. Johnson (2010), World Ocean Atlas 2009, vol. 1, Temperature, NOAA Atlas NESDIS, vol. 68, edited by S. Levitus, 184 pp., NOAA, Silver Spring, Md.

Mauritzen, C., J. Price, T. Sanford, and D. Torres (2005), Circulation and mixing in the Faroese Channels, Deep Sea Res., Part I, 52, 883-913.

Mullarney, J. C., R. W. Griffiths, and G. O. Hughes (2004), Convection driven by differential heating at a horizontal boundary, J. Fluid Mech. 516, 181-209.

Munk, W. H. (1966), Abyssal recipes, Deep Sea Res. Oceanogr. Abstr., 13, 707-730.

Orsi, A. H., G. C. Johnson, and J. L. Bullister (1999), Circulation, mixing, and production of Antarctic Bottom Water, Prog. Oceanogr., 43, 55-109.

Paparella, F., and W. R. Young (2002), Horizontal convection is nonturbulent, J. Fluid Mech., 466, 205-214.

Park, Y., and K. Bryan (2000), Comparison of thermally driven circulation from a depth-coordinate model and an isopycnal model. Part I: Scaling law sensitivity to vertical diffusion, J. Phys. Oceanogr., 30, 590-605.

Rossby, H. T. (1965), On thermal convection driven by non-uniform heating from below: An experimental study, Deep Sea Res. Oceanogr. Abstr., 12, 9-16.

Ryan, W. B. F., et al. (2009), Global Multi-Resolution Topography (GMRT) synthesis data set, Geochem. Geophys. Geosyst., 10, Q03014, doi:10.1029/2008GC002332.

Saunders, P. M. (1996), The flux of dense cold water overflow water southeast of Iceland, J. Phys. Oceanogr., 26, 85-95.

Saunders, P. M. (2001), The dense northern overflows, in Ocean Circulation and Climate, Int. Geophys. Ser., vol. 77, pp. 401-418, Academic, San Diego, Calif.

Schott, F. A., R. Zantopp, L. Stramma, M. Dengler, J. Fischer, and M. Wibaux (2004), Circulation and deep-water export at the western exit of the subpolar North Atlantic, J. Phys. Oceanogr., 34, 817-843.

Stommel, H. (1962), On the smallness of sinking regions in the ocean, Proc. Natl. Acad. Sci. U. S. A., 48, 766-772.

Voet, G., and D. Quadfasel (2010), Entrainment in the Denmark Strait overflow plume by meso-scale eddies, Ocean Sci., 6, 301-310.

Wang, W., and R. X. Huang (2005), An experimental study on thermal convection driven by horizontal differential heating, J. Fluid Mech. 540, 49-73.

Wells, M., C. Cenedese, and C. P. Caulfield (2010), The relationship between flux coefficient and entrainment ratio in density currents, J. Phys Oceanogr., 40, 2713-2727, doi:10.1175/2010JPO4225.1.

Whitehead, J. A. (1998), Topographic control of oceanic flows in deep passages and straits, Rev. Geophys., 36(3), 423-440.

Winton, M. (1995), Why is the deep sinking narrow?, J. Phys. Oceanogr. 25, 997-1005

Wong, A. B. D., and R. Griffiths (2001), Two-basin filling boxes, J. Geophys. Res., 106(C11), 26,929-26,941.

R. W. Griffiths, G. O. Hughes, and K. D. Stewart, Research School of Earth Sciences, Australian National University, Jaeger Bldg. 7, Mills Road, Acton, ACT 0200, Australia. (kial.stewart@anu.edu.au) 